\title{
Use of Human Surfactant Low Molecular Weight Apoproteins in the Reconstitution of Surfactant Biologic Activity
}

\author{
Susan D. Revak," T. Allen Merritt, Eric Degryse,' Lorette Stefani,' Michael Courtney," \\ Mikko Hallman," and Charles G. Cochrane* \\ *Department of Immunology, Research Institute of Scripps Clinic, La Jolla, California 92037; ${ }^{\ddagger}$ Division of Neonatal/Perinatal \\ Medicine, Department of Pediatrics, University of California at San Diego (UCSD), San Diego, California 92103; \\ ${ }^{\S}$ Department of Molecular and Cellular Biology, Transgene, 67082 Strasbourg Cedex France; \\ and "Children's Hospital, The University of Helsinki, Helsinki, Finland
}

\section{Abstract}

Two low molecular weight (LMW) apoproteins were isolated from human pulmonary surfactant. SDS polyacrylamide gel analysis showed one protein (SP 18) to have an apparent molecular weight of 18,000 when unreduced and 9,000 $\mathrm{D}$ after reduction. The second protein (SP 9) migrated at $\sim 9,000 \mathrm{D}$ in the presence or absence of reducing agents. Both proteins contain a high number of hydrophobic amino acids. The $\mathbf{N H}_{2}$-terminal sequence of SP 18 was determined to be: $\mathrm{NH}_{2}$-phe-proile-pro-leu-pro-tyr-. A cDNA clone isolated from a human adult lung cDNA library contained a long open reading frame encoding at an internal position the human SP 18 amino-terminal sequence.

Mixtures of phospholipids (PL) and SP 9 and SP 18 were assessed for their capacity to reduce surface tensions on a pulsating bubble surfactometer. The addition of $1 \%$ apoprotein resulted in a reduction of surface tension after $15 \mathrm{~s}$ from $\mathbf{4 2 . 9}$ dyn/cm for PL alone to 16.7 and $6.3 \mathrm{dyn} / \mathrm{cm}$ for preparations containing SP 9 and SP 18, respectively. In vivo assessment of reconstituted surfactant activity was performed in fetal rabbits. Reconstituted surfactant consisting of PL $+0.5 \%$ SP 18 instilled intratracheally at delivery resulted in a marked increase in lung compliance, while the incorporation of $0.5 \%$ SP 9 yielded a moderate increase. These data show the ability to produce biologically active surfactant by the addition of isolated LMW apoproteins to defined PL.

\section{Introduction}

Pulmonary surfactant, which lines the alveolar epithelium of mature mammalian lungs, has been shown to be a lipoprotein complex capable of reducing surface tension at the air-liquid interface $(1,2)$. The apoproteins present in this complex have been the subject of many studies over the past few years which have helped to elucidate the physiologic role they play in surfactant activity. While initial interest seemed focused primarily on a 35,000-D major glycoprotein (3-17), more recent studies have described hydrophobic 5,000-18,000-D apoproteins (18-27) which may, in fact, be more important in the

This is publication No. 4720-IMM from the Department of Immunology, Research Institute of Scripps Clinic. Address reprint requests to Dr. Revak.

Received for publication 25 June 1987 and in revised form 28 September 1987.

J. Clin. Invest.

(c) The American Society for Clinical Investigation, Inc. 0021-9738/88/03/0826/08 \$2.00

Volume 81, March 1988, 826-833 expression of surfactant surface tension reduction activity. These low molecular weight (LMW) ${ }^{1}$ apoproteins, one of which has been described as a "proteolipid" (21), can be found in several organic surfactant lipid extracts being tested clinically (Tokyo Tanabe's "surfactant TA," calf lung surfactant extract) that have also been shown not to contain the 35,000-D apoprotein $(20,23,25)$. That the 35,000-D and the LMW apoproteins of surfactant are distinct has been shown immunologically (22-26), and different amino acid compositions (4, $8,14,16,17,19,21,23,25)$ have been reported. In the canine system, two unique amino acid sequences have been derived from cDNA clones $(27,28)$. While it is apparent that the LMW apoproteins represent a group of proteins clearly distinguishable from the 35,000-D surfactant apoprotein, it is not clear as to whether this group is comprised of one or more apoproteins and what differences exist in their characteristics and functions if there are multiple proteins.

We have previously reported the isolation of the 35,000-D protein from human amniotic fluid surfactant and studied its ability when added to phospholipids to lower the surface tension of a pulsating bubble and to increase lung compliance and alveolar expansion when instilled into fetal rabbits (17). In the current study we have isolated two LMW apoproteins from human amniotic fluid surfactant, partially characterized them, and used the same pulsating bubble and fetal rabbit models to show that each can be recombined with synthetic phospholipids (PL) to yield a functionally active reconstituted surfactant. Furthermore, a cDNA clone corresponding to the larger apoprotein has been isolated and its nucleotide sequence determined. We will refer to these two distinct LMW apoproteins as surfactant protein (SP) 18 and SP 9, with the number following SP indicating the molecular weight (in kilodaltons) of the protein as it appears in unreduced SDS-PAGE.

\section{Methods}

Purification of $L M W$ apoproteins. Human pulmonary surfactant was isolated from full-term amniotic fluid and applied to a column of DEAE-Sephacel A-50 (Pharmacia Fine Chemicals, Uppsala, Sweden) using $4 \mathrm{ml}$ packed volume per $200 \mathrm{mg}$ surfactant, in a Tris-EDTA buffer containing $1 \% n$-octyl-beta-D-glucopyranoside as previously described $(17,29)$. This particular column and conditions were used to isolate the 35,000-D apoprotein (for use in other studies) without exposing it to potentially denaturing organic solvents. The void volume, containing the lipids and proteins that did not bind to the column under these conditions, was pooled and extracted with an equal vol-

1. Abbreviations used in this paper: DPPC, dipalmitoylphosphatidylcholine; LMW, low molecular weight; PG, phosphatidylglycerol; PL, phospholipid(s); SP, surfactant protein. 
ume of 2:1 chloroform/methanol. After centrifugation to separate the phases, the upper phase (water plus methanol) was reextracted with one-half volume chloroform. After centrifugation, the resultant lower organic phase was added to the initial lower phase and evaporated to dryness under a stream of nitrogen. This extract, which contained 100-180 mg PL, LMW apoproteins, and octylglucopyranoside, was redissolved in $2.5 \mathrm{ml}$ chloroform/methanol (2:1). Following the method of Takahashi and Fujiwara (21), which we found to afford a good separation of octylglucopyranside from the LMW proteins and $\mathrm{PL}$, a glass column $2.5 \mathrm{~cm}$ in diameter was packed at $4^{\circ}$ to a height of $38 \mathrm{~cm}$ with Sephadex LH-20 (Pharmacia Fine Chemicals) in 2:1 chloroform/methanol. The sample was loaded and 2-ml fractions collected as chloroform/methanol $(2: 1)$ was run through at a flow rate of 8.5 $\mathrm{ml} / \mathrm{h}$. PL eluted after $40 \mathrm{ml}$ of buffer had passed through the column. Octylglucopyranoside appeared at the 56-116 ml region. The PL region was pooled, dried under nitrogen, and redissolved in $1 \mathrm{ml}$ chloroform. A silicic acid column was prepared by packing $9 \mathrm{ml}$ of Bio-Sil HA (Bio-Rad Laboratories, Richmond, CA) in chloroform in a glass column at room temperature. The sample (which contained $\sim 50 \mathrm{mg}$ PL) was applied and washed with $11 \mathrm{ml}$ chloroform. A linear gradient of increasing methanol was established using an equal weight of chloroform and methanol $(38.8 \mathrm{~g}, 26.5 \mathrm{ml}$ chloroform and $50 \mathrm{ml}$ methanol). Fractions of $2 \mathrm{ml}$ were collected as the gradient was applied to the column. Fig. 1 shows the protein and PL profiles obtained. PL analyses showed a small peak in fractions 17 to 20 and a major peak after fraction 30. The Pierce BCA protein assay (see below) was positive in fractions 12 to 19 and 28 to 33 , but the latter peak is likely to be due to the PL present in this region. Electrophoresis in SDS polyacrylamide gels showed the LMW apoproteins were present in fractions 13 to 19 with some separation occurring between SP 9 and SP 18 . Alternatively, a method devised by Hawgood et al. (27) using a butanol extraction of surfactant followed by chromatography on Sephadex LH-20 in an acidified chloroform/methanol buffer, could be used to isolate the LMW apoprotein mixture. For some studies, a separation of the two LMW apoproteins was effected using Sephadex LH-60 (Shiffer, K., and S. Hawgood, personal communication). A glass column of $1 \mathrm{~cm}$ diam was packed to $40 \mathrm{~cm}$ with Sephadex LH-60 (Pharmacia Fine Chemicals) in chloroform/methanol (1:1) containing $5 \% 0.1 \mathrm{~N} \mathrm{HCl}$. A flow rate of $1-2 \mathrm{ml} / \mathrm{h}$ was used. A mixture of the $\mathrm{LMW}$ apoproteins (200-700 $\mu \mathrm{g}$ ) from either the Bio-Sil HA column or the LH-20 column described by Hawgood et al. (27), in a volume of $0.5 \mathrm{ml}$ buffer was applied to the top of the column, and fractions of $0.5 \mathrm{ml}$ were collected. Typically, SP 18 protein eluted in fractions 16 to 19 and SP 9 in fractions 24 to 29 . Appropriate fractions were pooled and dried in glass tubes under nitrogen. A brief period of lyophilization ensured complete removal of the $\mathrm{HCl}$. Proteins were resolubilized in methanol before use.

SDS-gel electrophoresis. Gel electrophoresis in $16 \%$ polyacrylamide was performed in the presence of SDS according to the method of Laemmli (30), using $3 \times 7-\mathrm{cm}$ minislab gels. $1 \% \beta$-mercaptoethanol was added to samples where indicated as a disulfide reducing agent. After electrophoresis, the gels were fixed overnight in 50\% methanol plus $12 \%$ acetic acid, washed in water for $2 \mathrm{~h}$, and silver-stained according to the method of Wray et al. (31).

Octylglucopyranoside assay. An assay for the quantitation of $n$ octyl-beta-D-glucopyranoside, based on the anthrone method of Spiro (32), has been described previously (17).

Protein determinations. Organic samples containing up to $5 \mu \mathrm{g}$ protein were dried in $12 \times 75-\mathrm{mm}$ glass tubes under nitrogen. $15 \mu \mathrm{l}$ of $1 \%$ SDS in $\mathrm{H}_{2} \mathrm{O}$ and $300 \mu \mathrm{l}$ BCA Protein Assay Reagent (Pierce Chemical Co., Rockford, IL) were added. Tubes were covered and incubated at $60^{\circ} \mathrm{C}$ for $30 \mathrm{~min}$. After cooling, the samples were transferred to a 96-well flat-bottom polystyrene microtiter plate and optical density at $550 \mathrm{~nm}$ measured. Bovine serum albumin was used as a standard. Note that some phospholipids will react in the BCA protein assay, making protein quantitations inaccurate when lipid is present (i.e., before Bio-Sil HA chromatography). Additionally, once purified, the hydrophobic LMW apoproteins themselves react poorly with the BCA reagents, and all quantitations of the isolated proteins were, therefore, based on amino acid compositions.

PL. Dipalmitoylphosphatidylcholine (DPPC, beta, gamma-dipalmitoyl-L-alpha-lecithin) and L-alpha-phosphatidyl-DL-glycerol (PG, derivative of egg lecithin) were purchased from either CalbiochemBehring Corp. (La Jolla, CA) or Avanti Polar-Lipids, Inc. (Birmingham, AL). DPPC was added to PG in chloroform in a weight ratio of 3:1.

Recombination of $L M W$ apoproteins with $P L$. For in vitro assays, a methanol solution containing $4 \mu \mathrm{g}$ of SP 9 or SP 18 , was added to 400 $\mu \mathrm{g} \mathrm{DPPC/PG}$ in chloroform in a $12 \times 75-\mathrm{mm}$ glass tube. After a brief vortex mixing, the samples were dried under $\mathrm{N}_{2} .90 \mu$ of water was added to each and the tubes placed in a $37^{\circ} \mathrm{C}$ water bath for $15 \mathrm{~min}$, with periodic gentle mixing. Isotonicity was restored with the addition of $10 \mu \mathrm{l}$ of $9 \% \mathrm{NaCl}$ to each sample before assay. For in vivo rabbit studies, $50 \mu \mathrm{g} \mathrm{LMW}$ apoproteins (containing both SP 9 and SP 18) or $25 \mu \mathrm{g}$ SP 9 or $25 \mu \mathrm{g}$ SP 18 were dried under $\mathrm{N}_{2} .5 \mathrm{mg}$ of PL (DPPC/PG, 3:1) was added in chloroform. The samples were mixed, dried, and resuspended in $250 \mu \mathrm{l} 100 \mathrm{mM}$ saline plus $1.5 \mathrm{mM} \mathrm{CaCl}_{2}$, to yield a reconstituted surfactant at $20 \mathrm{mg} / \mathrm{ml}$ with $0.5-1 \%$ protein.

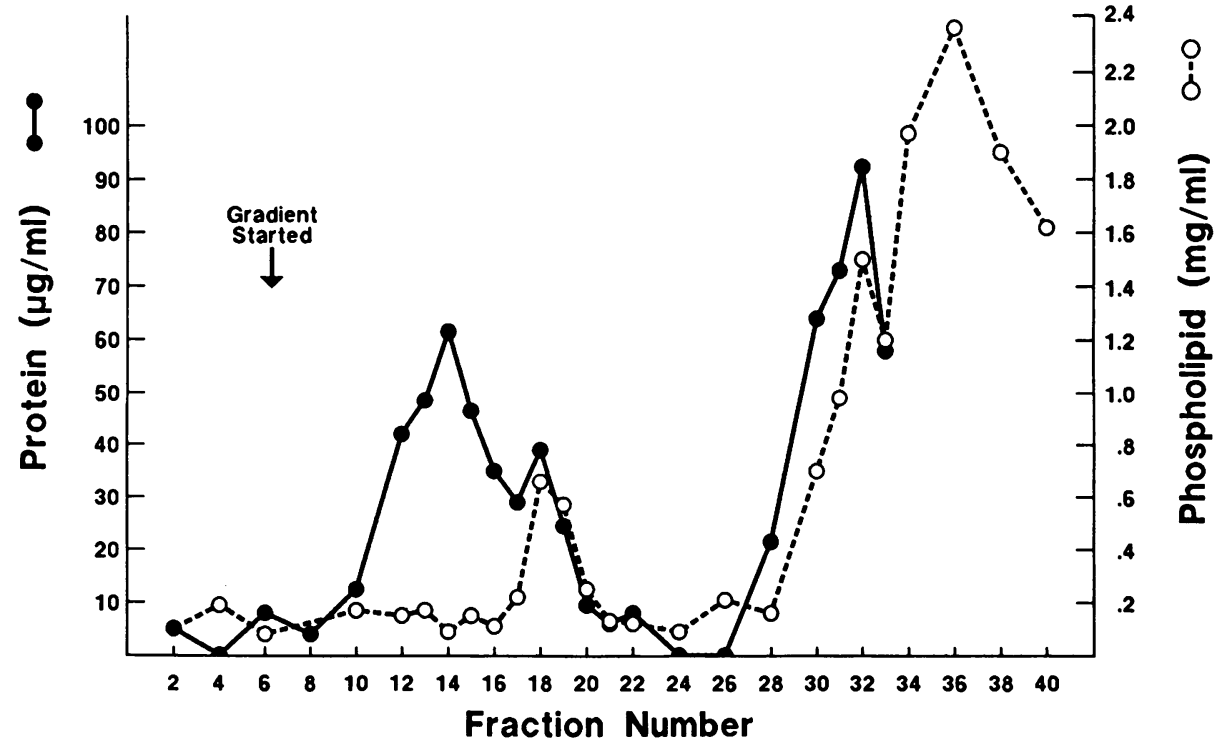

Figure 1. Bio-Sil HA (silicic acid) column. Results of Pierce BCA protein assay (solid line) and PL analyses (dashed line) are shown for selected fractions. $2 \mathrm{ml}$ was collected per fraction. Positive protein assay in fractions 28 to 33 is due to the presence of PL (see text). 
Surfactant activity assays. In vitro assays of surfactant activity, assessed as its ability to lower the surface tension of a pulsating bubble, and in vivo assays using fetal rabbits, have both been described in detail previously (17).

Morphometric analyses. Fetal rabbit lungs, inflated to $30 \mathrm{~cm} \mathrm{H}_{2} \mathrm{O}$ and then deflated to $10 \mathrm{~cm} \mathrm{H}_{2} \mathrm{O}$, were submerged in $10 \%$ formalin for $72 \mathrm{~h}$. Parafin sections were oriented from apex to base and $5-\mu \mathrm{m}$ sections taken anterior to posterior. After hematoxylin and eosin staining, 10 fields $(\times 100)$ were point-counted from apex to base on multiple sections. Standardized morphometric methods (33) were used to determine ratios of lung interstitium to air spaces for each treatment group. Intersections of alveolar perimeters were also determined.

$P L$ phosphorus assays. PL were quantitated according to the method of Bartlett (34).

Amino acid analysis. Triplicate samples for amino acid compositions were hydrolyzed with $\mathrm{HCl}$ at $110^{\circ} \mathrm{C}$ for $24 \mathrm{~h}$, with $\mathrm{HCl}$ at $150^{\circ} \mathrm{C}$ for $24 \mathrm{~h}$, or in performic acid at $110^{\circ} \mathrm{C}$ for $24 \mathrm{~h}$, followed by $\mathrm{HCl}$ hydrolysis at $110^{\circ} \mathrm{C}$ for $24 \mathrm{~h}$. Analyses were performed on an amino acid analyzer (model 121-M; Beckman Instruments, Inc., Fullerton, CA). Tryptophan was not determined.

Amino acid sequencing. Vapor-phase protein sequencing was performed on an amino acid sequencer (470A; Applied Biosystems, Inc., Foster City, CA) with an on-line model 120A HPLC.

Isolation of cDNA clones for human SP 18. RNA was prepared according to Chirgwin et al. (35) from a sample of unaffected adult lung tissue obtained during surgical removal of a neoplastic lesion. Preparation of double-stranded cDNA was carried out using standard techniques $(36,37)$ and a library was constructed in lambda NM607 as described (38). SP 18 clones were identified by screening phage plaques with synthetic oligonucleotide probes (39) that were prepared using an automated synthesizer (Applied Biosystems, Inc.) and purified by HPLC. Initial candidate clones were obtained using probe TG996 (5'CATTGCCTGTGGTATGGCCTGCTC 3'), which was derived from the partial nucleotide sequence of a small human surfactant apoprotein cDNA (40). Larger clones (up to $1.5 \mathrm{~kb}$ ) were isolated using probe TG1103 (5'TCGAGCAGGATGACGGAGTAGCGC 3'), which was based on the $5^{\prime}$ sequence of one of the original clones. The nucleotide sequence of the CDNA clones was determined by the chain termination method (41) using Eco RI restriction fragments subcloned in an appropriate $\mathrm{M} 13$ vector.

\section{Results}

Characteristics of the LMW apoproteins. The LMW apoproteins isolated from human amniotic fluid appeared after silicic acid chromatography, or after the Sephadex LH-20 column chromatography described by Hawgood et al. (27), as two protein bands in SDS-PAGE under nonreducing conditions. The upper band, having a weight of $18,000 \mathrm{D}$ and therefore termed SP 18 , is a dimer, and with the addition of $\beta$-mercaptoethanol, reduced to 9,000 D (Fig. 2). The other LMW apoprotein, which we will call SP $9,{ }^{2}$ appears as a diffuse band between 9,000 and $12,000 \mathrm{D}$ in the presence or absence of reducing agents. These two proteins could be separated by chromatography on Sephadex LH-60. The resultant purified proteins are shown in Fig. 2.

Amino acid compositions were determined for SP 18 and SP 9. Because of the extremely hydrophobic nature of these proteins, $\mathrm{HCl}$ hydrolysis was performed at $150^{\circ} \mathrm{C}$ for $24 \mathrm{~h}$, in addition to the standard $110^{\circ} \mathrm{C} 24-\mathrm{h}$ hydrolysis, and values for valine, leucine, and isoleucine were calculated from analyses

2. This is probably the same protein as that designated SAP-6 by Whitsett and co-workers (24), SP 5-8 by Hawgood and co-workers (27), and PSP-6 by Phelps et al. (25).

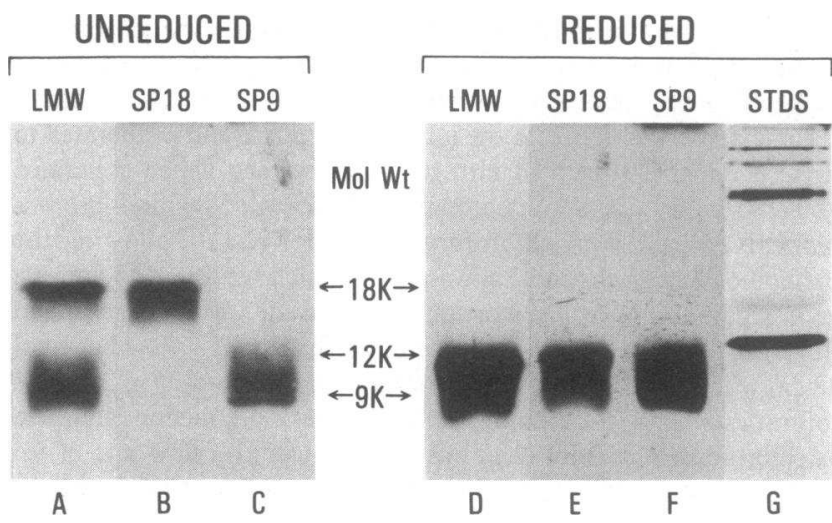

Figure 2. Silver-stained SDS-PAGE of LMW apoproteins. Lanes $A$ and $D$ show a sample after silicic acid or Sephadex LH-20 chromatography; both LMW proteins are present. Lanes $B, C, E$, and $F$ show the resolution of SP 18 (lanes $B$ and $E$ ) and SP 9 (lanes $C$ and $F$ ) after chromatography on Sephadex LH-60. Molecular weight standards are shown in lane $G$. Lanes $A-C$ are unreduced samples, and lanes $D-F$ contain identical samples reduced with $\beta$-mercaptoethanol before electrophoresis.

of the hydrolysates done under the extreme conditions. As shown in Table I, both proteins are extremely hydrophobic, with high levels of valine and leucine.

Amino-terminal sequence analysis of SP 18 yielded the following sequence: $\mathrm{NH}_{2}$-phe-pro-ile-pro-leu-pro-tyr-

Repeated sequencing of the purified SP 9 protein showed multiple peptides, all rich in leucine and containing at least six consecutive valines. $\mathrm{NH}_{2}$-terminal analysis showed phenylalanine, glycine, and isoleucine, with the relative amounts of each varying from preparation to preparation.

Nucleotide sequence analysis of SP 18 cDNA. The nucleotide sequence of an SP 18 cDNA clone is presented in Fig. 3. The sequence displays $83 \%$ homology with the canine SP 18 cDNA (27). A sequence within a large open reading frame was identified which matches perfectly with the amino terminus of SP 18, as determined by Edman degradation of the isolated protein (underlined in Fig. 3). This suggests that mature SP 18 arises by processing of a larger precursor molecule. In the mature sequence there is a single potential $N$-glycosylation site (Asn 110), no sites for tyrosine sulfation, and no G-X-Y repeats as found in the 35,000-D apoprotein (15). The molecular weight of 9,000 obtained by SDS-PAGE of reduced SP 18 is lower than that predicted for the complete sequence with amino terminus $\mathrm{NH}_{2}$-Phe-Pro-Ile-Pro-Leu-Pro-Tyr (19,772 D), implying further processing in the region of amino acids 70 to 90. In support of this, the theoretical amino acid composition (column 4, Table I) of a putative 9,000-D protein comprising residues 1 to 81 compares well with the determined values for purified SP 18. Note, however, that the carboxy terminus is, at this time, unknown. The amino-terminal portion of the protein (residues 1 to 81 ) is alkaline and more hydrophobic than the $\mathrm{COOH}$-terminal portion (residues 82 to 181): the Kyte-Doolittle index for residues 1 to 81 is 9,100 (pI, 8.6 ), and is $-3,000$ (pI, 5.91) for residues 82 to 181 (42). The amino terminus (residues 1 to 81 ) is, as in the canine sequence (27), composed of three hydrophobic domains: residues 1 to 11,22 to 49 , and 53 to 74 . These are interspersed with a charged domain (residues 12 to 21 ) and two hydrophilic and charged stretches (residues 47 to 54 and 72 to 81 ). 
Table I. Amino Acid Composition of Human SP 9 and SP 18 and a Comparison with the Theoretical Composition of SP 18*

\begin{tabular}{|c|c|c|c|}
\hline Amino acid & $\begin{array}{c}\mathrm{SP} 9 \\
\text { (residues/100) }\end{array}$ & $\begin{array}{c}\mathrm{SP} 18 \\
\text { (residues/100) }\end{array}$ & $\begin{array}{c}\mathrm{SP} 18^{*} \\
\text { (residues/100) }\end{array}$ \\
\hline Aspartic acid (or asparagine) & 1.1 & 3.4 & 3.7 \\
\hline Threonine & 0.8 & 1.5 & 1.2 \\
\hline Serine & 1.8 & 2.7 & 2.5 \\
\hline Glutamic acid (or glutamine) & 1.5 & 6.7 & 6.2 \\
\hline Proline & 8.3 & 7.8 & 7.4 \\
\hline Glycine & 10.6 & 6.1 & 4.9 \\
\hline Alanine & 4.9 & 10.2 & 9.9 \\
\hline Cysteine $^{\ddagger}$ & 9.1 & 7.2 & 8.6 \\
\hline Valine ${ }^{\S}$ & 12.2 & 11.7 & 11.1 \\
\hline Methionine & 3.4 & 3.2 & 3.7 \\
\hline Isoleucine $e^{\S}$ & 6.8 & 6.4 & 7.4 \\
\hline Leucine ${ }^{\S}$ & 22.4 & 17.4 & 17.3 \\
\hline Tyrosine & 0.7 & 2.2 & 2.5 \\
\hline Phenylalanine & 2.6 & 1.5 & 1.2 \\
\hline Histidine & 5.4 & 0 & 0 \\
\hline Lysine & 4.7 & 3.0 & 2.5 \\
\hline Arginine & 3.9 & 9.0 & 8.6 \\
\hline Tryptophan & ND & ND & 1.2 \\
\hline
\end{tabular}

Tryptophan was not determined.

* Theoretical composition based on sequence data through residue 81 .

* Determined after performic acid and $\mathrm{HCl}$ hydrolyses.

${ }^{8}$ Determined after $24 \mathrm{~h} \mathrm{HCl}$ hydrolysis at $150^{\circ} \mathrm{C}$.

Reconstitution of surfactant activity with LMW apoproteins. Samples were prepared containing $400 \mu \mathrm{g} / 100 \mu \mathrm{l} \mathrm{PL}$ (DPPG/PG, 3:1 by weight), PL plus $4 \mu \mathrm{g}$ SP 9, or PL plus $4 \mu \mathrm{g}$ SP 18. Each sample was assayed in the pulsating bubble surfactometer for the ability to lower surface tension. The results are shown in Table II as the mean minimal surface tension at $15 \mathrm{~s}, 1 \mathrm{~min}$, and $5 \mathrm{~min}$. Natural human surfactant, isolated from term amniotic fluid, diluted to $4 \mathrm{mg} / \mathrm{ml}$, is shown for comparison. While neither PL nor LMW apoproteins alone had significant surface tension-lowering capacities, a mixture of PL with either SP 9 or SP 18 showed significant activity. Recombining the PL with $1 \%$ by weight of SP 18 lowered the surface tensions measured to levels comparable with those obtained with an equal amount of natural human surfactant $(6.3$ $\pm 0.2 \mathrm{dyn} / \mathrm{cm}$ for PL plus SP 18 at $15 \mathrm{~s}, 2.0 \pm 1.2 \mathrm{dyn} / \mathrm{cm}$ for natural surfactant). On an equal weight basis, SP 9 lowered surface tension less effectively $(16.7 \pm 0.8 \mathrm{dyn} / \mathrm{cm}$ at $15 \mathrm{~s})$.

In vivo assays of recombinant surfactant activity were performed by instilling into the airways of immature fetal rabbits saline solutions containing $\mathrm{Ca}^{++}$alone or with the addition of PL, PL plus LMW apoproteins, or natural human surfactant. The animals were ventilated for $30 \mathrm{~min}$ and then degassed by placement in a bell jar under vacuum. The lungs were then inflated to given pressures and the volume of air required for each pressure was noted. The volumes required for given pressures during deflation from $30 \mathrm{~cm} \mathrm{H}_{2} \mathrm{O}$ were likewise determined. The resulting pressure/volume curves are shown in Fig. 4 for animals that received reconstituted surfactant made with purified SP 9 or SP $18(0.5 \%$ by weight compared with total phospholipid concentration) and appropriate control animals. Improved lung compliance is apparent in those animals treated with natural or either reconstituted surfactant as compared with those receiving saline or PL, with the SP 18 ap-
CAC CTG GGC CTG TGC AAA TCC CGg CAG CCA GAG CCA GAG CAG GAG His Leu Gly Leu Cys Lys Ser Arg Gln Pro Glu Pro Glu Gln Glu $-62$

CCA GGG ATG TCA GAC CCC CTG CCC AAA CCT CTG CGG GAC CCT CTG pro gly met ser Asp pro leu pro lys pro leu Arg Asp pro leu

CCA GAC CCT CTG CTG GAC AAG CTC GTC GTC CCT GTG CTG CCC GGG Pro Asp pro leu leu Asp lys leu val Val pro Val leu pro Gly

GCC CTC CAG GCG AGG CCT GGG CCT CAC ACA CAG GAT CTC TCC GAC Ala Leu Gln Ala Arg Pro Gly Pro His Thr Gln Asp Leu Ser Glu

CAG CAA TTC CCC ATT CCT CTC CCC TAT TGC TGG CTC TGC AGG GCT Gin Gin Phe Pro Ile Pro Leu Pro Tyr Cys Trp Leu Cys Arg Ala $-1 \frac{1}{1}$

CTG ATC AAG CGG ATC CAA GCC ATG ATT CCC MAG GGT GCG CTA GCT Leu Ile Lys Arg Ile Gin Ala Met Ile Pro Lys Gly Ala Leu Ala

GTG GCA GTG GCC CAG GTG TGC CGC GTG GTA CCT CTG GTG GCG GGC Val Ala Val Ala Gln Val Cys Arg Val Val Pro Leu Val Ala Gly

GGC ATC TGC CAG TGC CTG GCT GAG CGC TAC TCC GTC ATC CTG CTC Gly Ile Cys Gln Cys Leu Ala Glu Arg Tyr Ser Val Ile Leu Leu

GAC ACG CTG CTG GGC CGC ATG CTG CCC CAg CTG GTC TGC CGC CTC Asp Thr Leu Leu Gly Arg Met Leu pro Gln Leu Val Cys Arg Leu

GTC CTC CGG TGC TCC ATG GAT GAC AGC GCT GGC CCA AGG TCG CCG val Leu Arg Cys Ser Met Asp Asp Ser Ala Gly Pro Arg Ser Pro

ACA GGA GAA TGg CTG CCG CGA GAC TCT GAg tGC CAC CTC TGC ATC Thr Gly Glu Trp Leu Pro Arg Asp Ser Glu Cys his Leu Cys Met TCC GTG ACC ACC CAG GCC GGG AaC AGC AGC GAG CAG GCC ATA CCA Ser Val Thr Thr Gln Ala Gly Asn Ser Ser Glu Gln Ala Ile Pro 110

CAG GCA ATG CTC CAG GCC TGT GTT GGC TCC TGG CTG GAC AGg GAA Gln Ala Met Leu Gln Ala Cys Val Gly Ser Trp Leu Asp Arq Glu AAG TGC AAG CAA TTT GTG GAG CAG CAC ACG CCC CAG CTG CTG ACC Lys Cys Lys Gln Phe Val Glu Gln His Thr Pro Gln Leu Leu Thr CTG GTG CCC AGG GGC TGG GAT GCC CAC ACC ACC TGC CAG GCC CTC Leu Val Pro Arg Gly Trp Asp Ala His Thr Thr Cys Gln Ala Leu GGA GTG TGT GGG ACC ATG TCC AGC CCT CTC CAG TGT ATC CAC AGC Gly Val Cys Gly Thr Met Ser Ser Pro Leu Gln Cys Ile His Ser CCC GAC CTT TGATGAGAaC TCAGCTGTCCA Pro Asp Leu

Figure 3. Sequence of the human SP $18 \mathrm{cDNA}$ clone and the deduced amino acid sequence. The $\mathrm{NH}_{2}$-terminal amino acid sequence determined by Edman degradation is underlined.

pearing more effective than SP 9 on an equal weight basis. A similar experiment was performed using a mixture of SP 9 and SP 18 for reconstitution. The results were almost identical to the PL plus SP 18 curve presented in Fig. 4. After compliance measurements, the lungs were inflated to $30 \mathrm{~cm} \mathrm{H}_{2} \mathrm{O}$, deflated back to $10 \mathrm{~cm} \mathrm{H}_{2} \mathrm{O}$, clamped, excised, and fixed in formalin. Thin sections were stained with hematoxylin and eosin and examined microscopically. As shown in Fig. 5, lungs treated with saline $(A)$ or $\operatorname{PL}(C)$ appeared atelectatic, while those from animals that received natural $(B)$ or reconstituted $(D)$ surfac-

Table II. Minimum Surface Tensions in the Pulsating Bubble*

\begin{tabular}{lrrr}
\hline & $15 \mathrm{~s}$ & $1 \mathrm{~min}$ & \multicolumn{1}{c}{$5 \mathrm{~min}$} \\
\hline $\mathrm{PL}^{\ddagger}$ & $42.9 \pm 1.4$ & $41.6 \pm 1.6$ & $34.9 \pm 4.9$ \\
$\mathrm{PL}+\mathrm{SP} \mathrm{9}$ & $16.7 \pm 0.8$ & $14.1 \pm 1.2$ & $12.2 \pm 1.0$ \\
PL + SP 18 & $6.3 \pm 0.2$ & $5.1 \pm 1.0$ & $4.9 \pm 0.6$ \\
Natural human surfactant" & $2.0 \pm 1.2$ & $2.4 \pm 1.4$ & $0.4 \pm 0.4$
\end{tabular}

* Pulsation of 20 cycles/min started $10 \mathrm{~s}$ after bubble formation. All values are in dyn $\cdot \mathrm{cm}^{-1}$ and are the average of at least three determinations.

‡ PL DPPC:PG, 3:1, $4 \mathrm{mg} / \mathrm{ml}$.

$\S 1 \%$ by weight compared with PL.

" Diluted to $4 \mathrm{mg} / \mathrm{ml}$ 


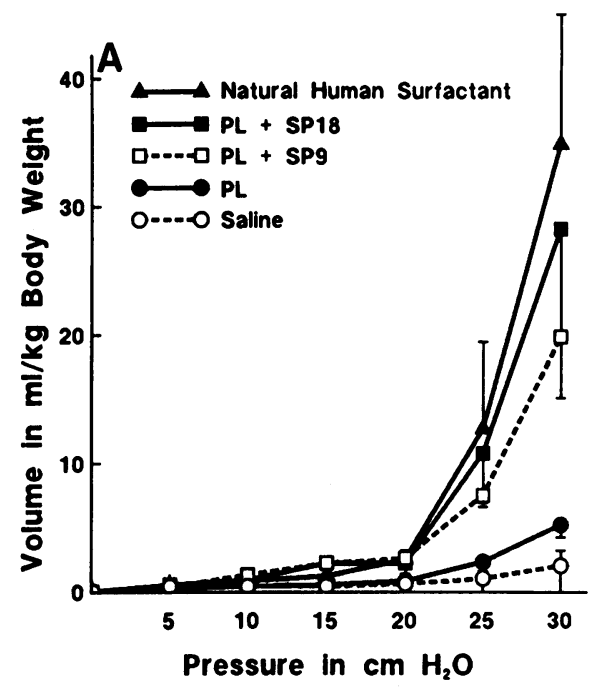



Figure 4. Inflation $(A)$ and deflation $(B)$ pressure/volume curves of fetal rabbit lungs $30 \mathrm{~min}$ after intratracheal instillation of $100 \mu \mathrm{l}$ of saline (0), $2 \mathrm{mg}$ PL DPPC:PG, 3:1 (๑), PL + $10 \mu \mathrm{g} \mathrm{SP} 9$ (口), PL + $10 \mu \mathrm{g}$ SP $18(\square)$, or $2 \mathrm{mg}$ natural human surfactant (४). Data are expressed as the mean of four animals $\pm 1 \mathrm{SD}$. tant showed normal alveolar expansion. Morphometric analyses of the thin sections showed an interstitium to air space ratio of 4.70 for saline treatment and 3.29 for phospholipids alone, as compared with 0.498 for natural surfactant and 0.538 for reconstituted surfactant. These data are shown in Table III and corroborate the significant $(P<0.001$; Mann-Whitney $U$ test) increase in air space seen in Fig. 5. A comparison of alveolar perimeters similarly demonstrated a significantly $(P<0.003)$ greater number of intersections of the alveolar boundaries in saline- or PL-treated fetuses compared with surfactant-treated animals.

\section{Discussion}

This report describes two LMW apoproteins isolated from human amniotic fluid surfactant that can be added to known PL to produce a biologically active surfactant. While we have referred to these proteins in the current study as SP 18 and SP 9, it is apparent from the recent literature that multiple nomenclature and an assortment of reported molecular weights (ranging from 5,000 to 18,000) exist (18-27). The apparent differences in physical properties may be explained by a variety of factors including species differences, varying purifica-

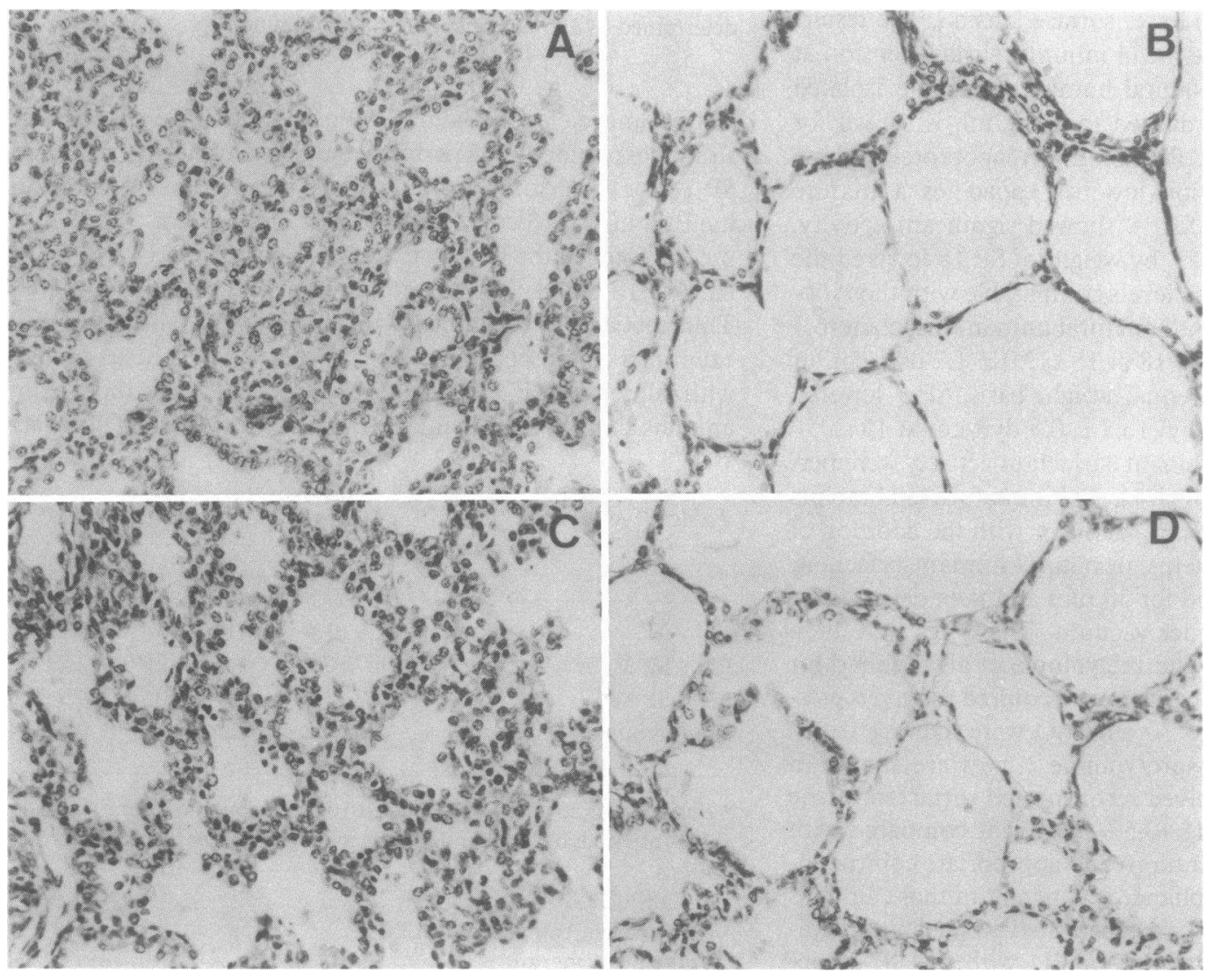

Figure 5. Fetal rabbit lungs $(\times 125$, hematoxylin-eosin stain) after treatment with saline $(A)$, natural human surfactant (B), PL DPPC:PG $(C)$, or PL plus LMW apoproteins (SP $9+$ SP 18) (D). 
Table III. Morphometric Analysis of Airspace after Fetal Rabbit Treatment

\begin{tabular}{lc}
\multicolumn{1}{c}{ Tracheal instillation } & Interstitium/air space \\
\hline Saline & 4.70 \\
$\mathrm{PL}^{*}$ & 3.29 \\
$\mathrm{PL}^{*}+$ LMW apoproteins & $\ddagger$ \\
Natural human surfactant & 0.538 \\
& 0.498
\end{tabular}

* $2 \mathrm{mg}$ of 3:1 DPPC:PG per animal.

$\$ 20 \mu \mathrm{g}$ of LMW apoproteins added to PL.

$\$ 2 \mathrm{mg}$ per animal.

tion and handling techniques, varying determinations of low molecular weights based on standards in SDS-polyacrylamide gels, and potential interference by lipids of LMW protein bands in gels. Comparisons of amino acid compositions and sequences and immunologic analyses using monospecific antibodies will help to sort out the LMW apoproteins. We feel that the SP 9 protein described here, giving a diffuse band on SDS-polyacrylamide gels from 9,000-12,000 D under reducing or nonreducing conditions, is probably the same protein as that designated SAP-6 by Whitsett and co-workers (24), SP 5-8 by Hawgood and co-workers (27), PSP-6 by Phelps et al. (25), and the 5-kD proteolipid of Takahashi and Fujiwara (21). The extremely hydrophobic nature of this protein is apparent from its amino acid composition (Table I) and sequence data, which show at least six consecutive valine residues preceded by a leucine-rich region. The presence of three amino-terminal residues (phenylalanine, glycine, and isoleucine) in our preparations of SP 9 derived from amniotic fluid surfactant suggests a collection of peptides having an identical sequence but having had one or two residues removed from the amino-terminus. Phelps et al. (25) have recently reported a similar finding with bovine PSP-6 apoprotein.

SP 18 appears to be a disulfide-linked dimer of two identical 9,000-D peptides (but different from the 9,000-D peptide of SP 9). A single $\mathrm{NH}_{2}$-terminal sequence, phe-pro-ile-proleu-pro-tyr-, was found. This sequence, with the exception of the $\mathrm{NH}_{2}$-terminal phenylalanine, is identical to that predicted by the canine SP $18 \mathrm{cDNA}$ clone isolated by Hawgood et al. (27). Amino acid composition (Table I) shows a high number of hydrophobic residues. When unreduced SDS-PAGE were overloaded with SP 18 protein, sequentially less intensely staining bands were seen at 36,000 and $56,000 \mathrm{D}$, suggesting oligomeric forms of the protein; upon reduction, only a single 9,000-D band was seen (unreported observations).

The nucleotide sequence of an SP 18 cDNA clone predicted that the apoprotein is synthesised as a large precursor that is cleaved to release a $19,722-\mathrm{D}$ protein carrying the $\mathrm{NH}_{2-}$ terminal sequence determined by Edman degradation. (Fig. 3). To obtain the 9,000-D mature polypeptide, a further cleavage near the center of the molecule would be necessary. Interestingly, if cleavage occurs between residues 72 and 98, an uneven number of cysteines would be present in either peptide, one of which may therefore be available for intermolecular bonding.

Comparison of the deduced amino acid sequence of the entire human SP 18 with the canine SP 18 sequence displays an overall homology of $71 \%$, with many of the differences involving conservative changes. There are two additional residues in canine SP 18 (molecular weight, 20,060) but no difference in pI (7.8). Significantly, all the cysteine and 13 of the 14 proline residues, both of which may be considered as major structural determinants, are conserved and occupy the same position in both proteins. Moreover, the amino-terminal region of the molecule is more conserved (83\% homology) between dog and man than the $\mathrm{COOH}$-terminus $(69 \%$ homology). This is consistent with the first half of the molecule harboring the biological activity.

Both SP 9 and SP 18 apoproteins, isolated as described above, could be shown to have biophysical activity after recombination with PL. The addition of $1 \%$ by weight of SP 18 to $\mathrm{DPPC} / \mathrm{PG}$ resulted in an immediate increase in surface pressure causing surface tensions of $<10 \mathrm{dyn} / \mathrm{cm}$ by $15 \mathrm{~s}$. The addition of $1 \%$ SP 9 to DPPC/PG was slightly less effective, lowering surface tensions to $16.7,14.1$, and $12.2 \mathrm{dyn} / \mathrm{cm}$ at 15 s, 1 and 5 min, respectively. Mixtures of both SP 18 and SP 9 were also effective, but further studies will be required to determine whether the combined effect is additive or synergistic.

In vivo studies of reconstituted surfactant using the fetal rabbit model (43) were performed using mixtures of SP 18 and SP 9 as well as each protein individually. A marked improvement in lung compliance was seen in animals treated with natural surfactant or reconstituted surfactant prepared with SP 18 apoprotein, as compared with those receiving PL alone or saline (Fig. 4). A moderate improvement was seen when SP 9 was used. Identical studies using a mixture of SP 18 and SP 9 to prepare the reconstituted surfactant showed results very similar to those obtained with SP 18 alone (solid squares, Fig. 4); however, the exact ratio of SP 18 and SP 9 in those studies could not be accurately ascertained. Fig. 5 shows representative microscopic alvelor fields, indicating the lack of atelectasis after surfactant instillation.

Suzuki et al. (19) have reported a reduction in surface tension (measured on the Wilhelmy balance or in a pulsating bubble), and a fivefold increase in tidal volumes of prematurely delivered rabbits at insufflation pressures of $25 \mathrm{~cm} \mathrm{H}_{2} \mathrm{O}$ when porcine LMW $(<15,000 \mathrm{D})$ surfactant apoproteins are added to mixtures of DPPC:DPPG) at a weight ratio of 5:80:20 (protein/DPPC/DPPG). Whether one or multiple proteins are present in this system is unclear.

Our previous studies using the 35,000-D apoprotein (17) also showed a moderate reduction in surface tension, similar to that obtained with SP 9 in the current studies. Clearly, further studies must be done using various combinations and concentrations of SP 18, SP 9, and the 35,000-D apoprotein, as well as $\mathrm{Ca}^{++}$and perhaps various PL to elucidate the interactions between these various components of surfactant and to determine the best conditions for a biologically active recombinant surfactant. Hawgood et al. (27) have shown in the canine system a synergistic, calcium-dependent effect on the stimulation of PL surface film formation by the addition of the 35,000-D apoprotein and the LMW apoproteins.

Improvements in lung function as measured by a decrease in mean airway pressure and oxygen requirements is an immediate effect also seen in human preterm infants treated with natural human surfactant $(29,44-46)$ or lipid extracts (containing LMW apoproteins) of bovine surfactant (47-52). The ability to reproduce the essential components of these surfactants via synthetic means (i.e., genetically engineered proteins combined with synthetic PL) would permit their use in the 
treatment of not only infant respiratory distress syndrome, but in other pathologic conditions as well, where an abnormality or shortage of pulmonary surfactant may play a crucial role.

\section{Acknowledgments}

The authors wish to acknowledge the support and cooperation of the San Diego Amniotic Fluid Bank, which is sponsored by the March of Dimes, and to thank the many mothers who donated amniotic fluid and the obstetricians and nurses who collected it at the following institutions: UCSD Medical Center, Grossmont Hospital, Naval Regional Medical Center, Scripps Memorial Hospital, Kaiser Hospital, and Sharp Hospital in San Diego, and University Central Hospital, Hospital of the Midwifery Institute, and the Jorvi Hospital in Helsinki. We thank also Ms. Katherine Holcomb and Ms. Ellen Riihela for their expert technical assistance in the isolation of surfactant from the amniotic fluid, Ms. Joan Sorg for phospholipid analyses, Mr. Mike Ballard for amino acid analyses, Mr. Tim Burke and Dr. Tom Edgington for amino acid sequencing, Dr. J. P. Lecocq for helpful discussions, Francine Jaeger and Gerlinde Lenzen for nucleotide sequencing, and Mrs. Monica Bartlett for manuscript preparation.

This work was supported by grants HD-16292, FDA-PHS 000112 , and HL-35036 from National Institutes of Health (NIH), by the March of Dimes, the General Clinical Research Center, UCSD, Division of Research Resources grant RR-00827 (NIH) (T. A. Merritt), The Finnish Academy, and by the Sigrid Juselius Foundation (M. Hallman).

Note added in proof. After submission of this manuscript two groups published similar cloning and sequence analyses of human SP 18: Glasser et al. (53) and Jacobs et al. (54).

\section{References}

1. Goerke, J. 1974. Lung surfactant. Biochim. Biophys. Acta. 344:241-261.

2. Shelley, S. A., J. U. Balis, J. E. Paciga, C. G. Espenoza, and A. V. Richmond. 1982. Biochemical composition of adult human lung surfactant. Lung. 160:195-206.

3. Benson, B. J., S. Hawgood, and M. C. Williams. 1984. Role of apoprotein and calcium ions in surfactant function. Exp. Lung. Res. 6:223-236.

4. Bhattacharyya, S. N., and W. S. Lynn. 1978. Isolation and characterization of a pulmonary glycoprotein from human amniotic fluid. Biochim. Biophys. Acta. 537:329-335.

5. Bhattacharyya, S. N., and W. S. Lynn. 1979. Structural characterization of a glycoprotein isolated from alveoli of patients with alveolar proteinosis. J. Biol. Chem. 254:5191-5198.

6. Floros, J. F., D. S. Phelps, and H. W. Taeusch. 1985. Biosynthesis and in vitro translation of the major surfactant-associated protein from human lung. J. Biol. Chem. 260:495-500.

7. Hawgood, S., B. J. Benson, and R. L. Hamilton, Jr. 1985. Effects of a surfactant-associated protein and calcium ions on the structure and surface activity of lung surfactant lipids. Biochemistry. 24:184190.

8. Katyal, S. L., and G. Singh. 1984. Structural and ontogenic relationships of rat lung surfactant apoproteins. Exp. Lung Res. 6:175-189.

9. Katyal, S. L., and G. Singh. 1979. An immunologic study of the apoproteins of rat lung surfactant. Lab. Invest. 40:562-567.

10. King, R. J., and M. C. MacBeth. 1981. Interactions of the lipid and protein components of pulmonary surfactant: role of phosphatidyl glycerol and calcium. Biochim. Biophys. Acta. 647:159-168.

11. King, R. J., M. C. Carmichael, and P. M. Horowitz. 1983. Reassembly of lipid protein complexes of pulmonary surfactant. Proposed mechanism of interaction. J. Biol. Chem. 258:10672-10680.

12. Metcalfe, I. L., G. Enhorning, and F. Possmayer. 1980. Pulmo- nary surfactant-associated proteins: their role in the expression of surface activity. J. Appl. Physiol. Respir. Environ. Exercise Physiol. 49:34-41.

13. Singh, G., and S. L. Katyal. 1984. Surfactant apoproteins: immunohistochemistry. In Advances in Immunohistochemistry. Vol. 7. R. A. De Leltis, editor. Mason Publishing Co., New York. 263-275.

14. Sueishi, K., and B. J. Benson. 1981. Isolation of a major apolipoprotein of canine and murine pulmonary surfactant. Biochemical and immunochemical characteristics. Biochim. Biophys. Acta. 665:442-453.

15. White, R. T., D. Damm, J. Miller, K. Spratt, J. Schilling, S. Hawgood, B. Benson, and B. Cordell. 1985. Isolation and characterization of the human pulmonary surfactant apoprotein gene. Nature (Lond.). 317:361-363.

16. Whitsett, J. A., W. Hull, G. Ross, and T. Weaver. 1985. Characteristics of human surfactant-associated glycoproteins A. Pediatr. Res. 19:501-508.

17. Revak, S. D., T. A. Merritt, M. Hallman, and C. G. Cochrane. 1986. Reconstitution of surfactant activity using purified human apoprotein and phospholipids measured in vitro and in vivo. Am. Rev. Respir. Dis. 134:1258-1265.

18. Phizackerley, P. J. R., M. H. Town, and G. E. Newman. 1979. Hydrophobic proteins of lamellated osmiophilic bodies isolated from pig lung. Biochem. J. 183:731-736.

19. Suzuki, Y., T. Curstedt, G. Grossmann, T. Kobayashi, R. Nilsson, K. Nohara, and B. Robertson. 1986. The role of the low-molecular weight ( $\leq 15000$ daltons) apoproteins of pulmonary surfactant. Eur. J. Respir. Dis. 69:336-345.

20. Taeusch, H. W., K. M. W. Keough, M. Williams, R. Slavin, E. Steele, A. S. Lee, D. Phelps, N. Kariel, J. Floros, and M. E. Avery. 1986. Characterization of bovine surfactant for infants with Respiratory Distress Syndrome. Pediatrics. 77:572-581.

21. Takahashi, A., and T. Fujiwara. 1986. Proteolipid in bovine lung surfactant: its role in surfactant function. Biochem. Biophys. Res. Commun. 135:527-532.

22. Yu, S.-H., and F. Possmayer. 1986. Reconstitution of surfactant activity by using the $6 \mathrm{kDa}$ apoprotein associated with pulmonary surfactant. Biochem. J. 236:85-89.

23. Whitsett, J. A., B. L. Ohning, G. Ross, J. Meuth, T. Weaver, B. A. Holm, D. L. Shapiro, and R. H. Notter. 1986. Hydrophobic surfactant-associated protein in whole lung surfactant and its importance for biophysical activity in lung surfactant extracts used for replacement therapy. Pediatr. Res. 20:460-467.

24. Whitsett, J. A., W. M. Hull, B. Ohning, G. Ross, and T. E. Weaver. 1986. Immunologic identification of a pulmonary surfactantassociated protein of molecular weight $=6000$ daltons. Pediatr. Res. 20:744-749.

25. Phelps, D. S., L. M. Smith, and H. W. Taeusch. 1987. Characterization and partial amino acid sequence of a low molecular weight surfactant protein. Am. Rev. Respir. Dis. 135:1112-1117.

26. Suzuki, Y., K. Kogishi, Y. Fujita, T. Kina, and S. Nishikawa. 1986. A monoclonal antibody to 15,000 dalton protein associated with porcine pulmonary surfactant. Exp. Lung Res. 11:61-73.

27. Hawgood, S., B. J. Benson, J. Schilling, D. Damm, J. A. Clements, and R. T. White. 1987. Nucleotide and amino acid sequences of pulmonary surfactant protein SP18 and evidence for cooperation between SP18 and SP28-36 in surfactant lipid adsorption. Proc. Natl. Acad. Sci. USA. 85:66-70.

28. Benson, B., S. Hawgood, J. Schilling, J. Clements, D. Damm, B. Cordell, and R. T. White. 1985. Structure of canine pulmonary surfactant apoprotein: cDNA and complete amino acid sequence. Proc. Natl. Acad. Sci. USA. 82:6379-6383.

29. Hallman, M., T. A. Merritt, H. Schneider, B. L. Epstein, F. Mannino, D. K. Edwards, and L. Gluck. 1983. Isolation of human surfactant from amniotic fluid and a pilot study of its efficacy in respiratory distress syndrome. Pediatrics. 71:473-482.

30. Laemmli, U. K. 1970. Cleavage of structural proteins during 
the assembly of the head of bacteriophage $\mathrm{T}_{4}$. Nature (Lond.). 227:680-685.

31. Wray, W., T. Boulikas, V. P. Wray, and R. Hancock. 1981. Silver staining of proteins in polyacrylamide gels. Anal. Biochem. 118:197-203.

32. Spiro, R. 1966. Analysis of sugars found in glycoproteins. Methods Enzymol. 8:3-5.

33. Weibel, E. R. 1979. Lung morphometrics. In Stereological Methods. Vol. I. Academic Press, Inc. New York. 33-58.

34. Bartlett, G. R. 1959. Phosphorus assay in column chromatography. J. Biol. Chem. 234:466-468.

35. Chirgwin, J. M., A. E. Przbyla, R. J. MacDonald, and W. J. Rutter. 1979. Isolation of biologically active ribonucleic acid from sources enriched in ribonuclease. Biochemistry. 18:5294-5299.

36. Kupper, H., W. Keller, C. Kurz, S. Forss, H. Schaller, R. Frauze, K. Strohmaier, O. Marquardt, V. G. Zaslavsky, and P. H. Hofschneider. 1981. Cloning of cDNA of major antigen of foot-andmouth disease virus and expression in E. coli. Nature (Lond.). 289:555-559.

37. Efstratiadis, A., and L. Villa-Komaroff. 1979. Cloning of double stranded DNA. In Genetic Engineering. J. K. Stelow and A. Hollaender, editors. Plenum Publishing Corp., New York. 1:15-49.

38. Le Bouc, Y., D. Dreyer, F. Jaeger, M. Binoux, and P. Sondermeyer. 1986. Complete characterization of the human IGF-I nucleotide sequence isolated from newly constructed adult cDNA library. FEBS (Fed. Eur. Biochem. Soc.) Letts. 196:108-112.

39. Benton, W. D., and R. W. Davis. 1977. Screening lambda gt recombinant clones by hybridisation to single plaques in situ. Science (Wash. DC). 196:180-182.

40. Schilling, J. W., R. T. White, B. Cordell, and B. J. Benson. 1986. Recombinant alveolar surfactant protein. International patent application. WO 86/03408.

41. Sanger, F., S. Nicklen, and A. R. Coulson. 1977. DNA sequencing with chain terminating inhibitors. Proc. Natl. Acad. Sci. USA. 74:5463-5467.

42. Kyte, J., and R. F. Doolittle. 1982. A simple method for displaying the hydropathic character of a protein. J. Mol. Biol. 157:105132.

43. Schneider, M., M. Hallman, K. Benirschke, and L. Gluck. 1982. Human surfactant: a therapeutic trial in premature rabbits. $J$. Pediatrics. 100:619-622.

44. Merritt, T. A., M. Hallman, K. Holcomb, D. Strayer, B. Bloom, S. Revak, and C. G. Cochrane. 1986. Human surfactant treatment of severe respiratory distress syndrome: pulmonary effluent indicators of lung inflammation. J. Pediatr. 108:741-745.

45. Hallman, M., T. A. Merritt, A. L. Jarvenpaa, B. Boynton, F. Mannino, L. Gluck, T. Moore, and D. Edwards. 1985. Exogenous human surfactant for treatment of severe respiratory distress syndrome: a randomized prospective clinical trial. J. Pediatr. 106:963969.

46. Merritt, T. A., M. Hallman, B. T. Bloom, C. Berry, K. Benirschke, D. Sahn, T. Key, D. Edwards, A. L. Jarvenpaa, M. Pohjavuori, K. Kankaanpaa, M. Kunnas, M. Paatero, J. Rapola, and J. Jaaskelainen. 1986. Prophylactic treatment of very premature infants with human surfactant. $N$. Engl. J. Med. 315:785-790.

47. Smyth, J. A., I. L. Metcalfe, P. Duffty, F. Possmayer, M. H. Bryan, and G. Enhorning. 1983. Hyaline membrane disease treated with bovine surfactant. Pediatrics. 71:913-917.

48. Enhorning, G., A. Shennan, F. Possmayer, M. Dunn, C. P. Chee, and J. Milligan. 1985. Prevention of neonatal respiratory distress syndrome by tracheal instillation of surfactant: a randomized clinical trial. Pediatrics. 76:145-153.

49. Fujiwara, T., H. Maeta, S. Chida, T. Morita, Y. Watabe, and T. Abe. 1980. Artificial surfactant therapy in hyaline-membrane disease. Lancet. i:55-59.

50. Kwong, M. S., E. A. Egan, R. H. Notter, and D. L. Shapiro. 1985. A double blind clinical trial of calf lung lipid for the prevention of hyaline membrane disease in extremely premature infants. Pediatrics. 76:585-592.

51. Shapiro, D. L., R. H. Notter, F. C. Morin, K. Deluga, L. M. Golub, R. Sinkin, K. Weiss, and C. Cox. 1985. A double blind, randomized trial of a calf lung surfactant extract administered at birth to very premature infants for the prevention of respiratory distress syndrome. Pediatrics. 76:593-599.

52. Fujiwara, T. 1984. Surfactant replacement in neonatal RDS. In Pulmonary Surfactant. B. Robertson, L. M. G. Van Golde, and J. Batenburg, editors. Elsevier Science Publishers, Amsterdam. 479-503. 53. Glasser, S. W., T. R. Korfhagen, T. Weaver, T. Pilot-Matias, J. L. Fox, and J. A. Whitsett. 1987. cDNA and deduced amino acid sequence of human pulmonary surfactant-associated proteolipid SPL (Phe). Proc. Natl. Acad. Sc. USA. 84:4007-4011.

54. Jacobs, K. A., D. S. Phelps, R. Steinbrink, J. Fisch, R. Kriz, L. Mitsock, J. P. Dougherty, H. W. Taeusch, and J. Floros. 1987. Isolation of a cDNA clone encoding a high molecular weight precursor to a 6-kDa pulmonary surfactant-associated protein. J. Biol. Chem. 262:9808-9811. 